\title{
Different strategies in anaerobic biodegradation of aromatic compounds: nitrate reducers versus strict anaerobes
}

\author{
Bodo Philipp ${ }^{\dagger}$ and Bernhard Schink* \\ Department of Biology, University of Konstanz, \\ Universitätsstr. 10, D-78457 Konstanz, Germany.
}

\section{Summary}

Mononuclear aromatic compounds are degraded anaerobically through pathways that are basically different from those used in the presence of oxygen. Whereas aerobic degradation destabilizes the aromatic $\pi$-electron system by oxidative steps through oxygenase reactions, anaerobic degradation is most often initiated by a reductive attack. The benzoyl-CoA pathway is the most important metabolic route in this context, and a broad variety of mononuclear aromatics, including phenol, cresols, toluene, xylenes and ethylbenzene, are channelled into this pathway through various modification reactions. Multifunctional phenolic compounds are metabolized via the reductive resorcinol pathway, the oxidative resorcinol pathway with hydroxyhydroquinone as key intermediate, and the phloroglucinol pathway. Comparison of the various pathways used for modification and degradation of aromatics in the absence of oxygen indicates that the strategies of breakdown of these compounds are largely determined by the redox potentials of the electron acceptors used, and by the overall reaction energetics. Consequently, nitrate reducers quite often use strategies for primary attack on aromatic compounds that differ from those used by sulfate-reducing, iron-reducing or fermenting bacteria.

\section{Introduction}

Aromatic compounds are widespread in nature as structural polymers (lignin), as functional units in biochemistry

Received 1 July, 2011; revised 21 October, 2011; accepted 21 October, 2011. *For correspondence. E-mail bernhard.schink@unikonstanz.de; Tel. (+49) 7531882140 ; Fax (+49) 7531884047. tPresent address: Institute of Molecular and Biotechnology, University of Münster, Corrensstr. 3, D-48149 Münster, Germany. (amino acids, coenzymes), and as secondary metabolites of plants, fungi and bacteria. Aromatic compounds also make up a major part of petrol and are applied on a broad basis in chemical industry. Despite their often unusual structure, only few of these synthetic compounds appear to cause environmental problems due to incomplete degradation. Especially bacteria have developed an impressive adaptative capacity to successfully degrade synthetic compounds, even those which show only little resemblance to pre-existing templates among natural compounds.

Aerobic degradation of aromatic compounds employs molecular oxygen for substrate activation in oxygenase reactions, leading to catechol, protocatechuate and gentisate as key intermediates. These phenolic intermediates are subject to ring cleavage in a further oxygenasedependent step, either between or vicinal to the hydroxy groups of the aromatic ring (Vaillancourt et al., 2006) leading to an unsaturated, open-chain carboxylic acid which undergoes further degradation, typically to an acetyl and a succinyl derivative.

In anoxic environments, oxygenases cannot operate, and anaerobic degradation of aromatics, if possible at all, has to take alternative, oxygen-independent paths. Mainly through the 1970s and 1980s (Healy and Young, 1978; 1979), anaerobic breakdown of numerous mononuclear aromatics was documented in detail, leading to the identification of three different key intermediates through which mononuclear aromatic compounds are channelled, i.e. benzoyl-CoA, resorcinol, and phloroglucinol (Schink et al., 1992; Boll et al., 2002). The common feature of most of these pathways is that the aromatic nucleus is destabilized via a reductive rather than an oxidative attack. The benzoyl-CoA pathway appears to be the most important one because a broad variety of compounds enters this path, including phenol, various hydroxybenzoates, phenylacetate, aniline, cresols and alkylbenzenes (Schink et al., 1992; Heider and Fuchs, 1997; Harwood et al., 1999).

Nonetheless, the chemical constraints of microbial activities in anoxic environments differ with the respective 
electron acceptor system available. Reduction of nitrate (through nitrite, $\mathrm{NO}, \mathrm{N}_{2} \mathrm{O}$ ) to $\mathrm{N}_{2}$ operates at an average standard redox potential $\left(E_{0}{ }^{\prime}\right)$ of $+750 \mathrm{mV}$ (close to that of $\mathrm{O}_{2} / \mathrm{H}_{2} \mathrm{O}$ at $+810 \mathrm{mV}$ ), reduction of $\mathrm{Fe}(\mathrm{OH})_{3}$ to $\mathrm{Fe}^{2+}$ $(\mathrm{pH} 7.0)$ at c. $+100 \mathrm{mV}$ (Widdel et al., 1993), sulfate reduction to sulfide at $E_{0}^{\prime}=-218 \mathrm{mV}$, and finally methanogenesis at $-244 \mathrm{mV}$. Thus, it appears plausible that also the biochemical strategies taken in anaerobic degradation of aromatics should differ within anoxic environments, depending on the respective electron acceptor system in use.

The field of anaerobic degradation of aromatic compounds has been discussed in several other reviews in the recent past (Schink et al., 2000; Boll et al., 2002; Gibson and Harwood, 2002; Boll and Fuchs, 2005; Boll, 2005a,b; Heider, 2007; Fuchs, 2008; Carmona et al., 2009). In the following overview, we want to focus on the different strategies taken in anaerobic microbial degradation of aromatic compounds by different metabolic types of bacteria, depending on the electron acceptor available for substrate oxidation. It turns out that, beyond the mere non-availability of oxygen, also the overall reaction energetics and the redox potential of the electron acceptor system in use have a profound influence on the biochemical strategies employed in degradation of aromatics.

\section{Benzoate}

Benzoate is degraded anaerobically by nitrate-reducing, sulfate-reducing, iron(III)-reducing and also by fermenting bacteria, which cooperate with methanogenic partners in a syntrophic manner. In all these cases, benzoate is first activated by a ligase enzyme to form benzoyl-CoA; this reaction consumes two ATP equivalents. In the nitrate reducer Thauera aromatica, the stability of the aromatic ring structure is overcome by a reduction reaction which forms cyclohexadiene carboxylCoA as the first identifiable product (class I benzoyl-CoA reductase, Fig. 1A; Koch and colleagues 1993; Boll and Fuchs, 1995) and consumes further two ATP equivalents. This energy is required to overcome the resonance energy of the benzene ring to form the cyclohexadiene derivative; the standard redox potential $\left(E_{0}{ }^{\prime}\right)$ of the benzoyl-CoA/cyclohexadiene carboxyl-CoA couple is at $-620 \mathrm{mV}$ (Schöcke and Schink, 1999) and the reaction is irreversible.

In the iron-reducing bacterium Geobacter metallireducens (Fig. 1B) the reduction of benzoyl-CoA involves an enzyme (class II benzoyl-CoA reductase), which contains tungsten, zinc (Wischgoll et al., 2005; Boll, 2005b) and selenocysteine (Peters et al., 2004). The primary reaction product is cyclohexadiene carboxyl-CoA as with the nitrate reducers (Peters et al., 2007a; Kung et al.,
A

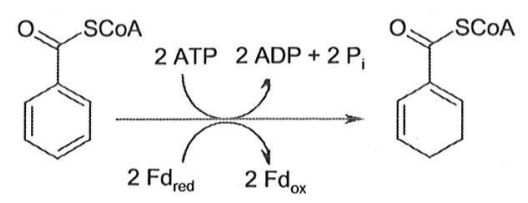

B

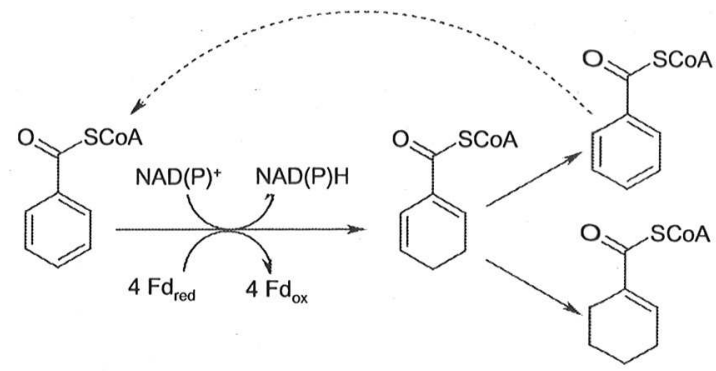

Fig. 1. Key steps in anaerobic degradation of benzoyl-CoA. A. Benzoyl-CoA reduction by the nitrate-reducing bacterium Thauera aromatica strain $\mathrm{K} 172$.

B. Benzoyl-CoA reduction by the iron-reducing bacterium Geobacter metallireducens.

2009), and the electrons for this reduction are supplied by a ferredoxin. The purified enzyme has no binding site for ATP, and ATP is not required (Fuchs, 2008; Kung et al., 2009). The ferredoxin electrons are dismutated through a 'bifurcation' mechanism (Herrmann et al., 2008; Thauer et al., 2008) to the level of benzoyl-CoA reduction $(-620 \mathrm{mV})$ and that of $\mathrm{NAD}(\mathrm{P}) \mathrm{H}(-320 \mathrm{mV})$; the NAD(P)H electrons have to be pushed again to the ferredoxin level, probably through an Rnf-like reversed electron transport system. The reaction equilibrium is shifted further by a subsequent highly exergonic dismutation of the dienoylCoA product to benzoyl-CoA and monoenoyl-CoA (A. Schmidt, pers. comm.). Thus, the overall reaction can be written as:

Benzoyl-CoA $+4 \mathrm{e}^{-}+4 \mathrm{H}^{+} \rightarrow$ Cylohex-1-ene carboxyl CoA

The redox potential of this reduction is at $-350 \mathrm{mV}$ (Schöcke and Schink, 1999). It was shown recently that the entire reaction chain is fully reversible (Kung et al., 2010), thus demonstrating that it operates close to the thermodynamic equilibrium.

Iron reducers gain substantially less energy in the further oxidation of the carbon skeleton than nitrate reducers do. Thus, it appears plausible that they employ an enzyme system for ring de-aromatization that operates with far less ATP expenditure than nitrate reducers do. The energetic situation of benzoate-degrading sulfate reducers is similar to that of iron reducers, and it is even worse with syntrophically fermenting benzoate degraders. To balance the overall energetics of benzoate fermentation by the syntrophically fermenting Syntrophus genti- 
A<smiles>CCc1cccc(CCCO)c1CC(C)O</smiles>

B

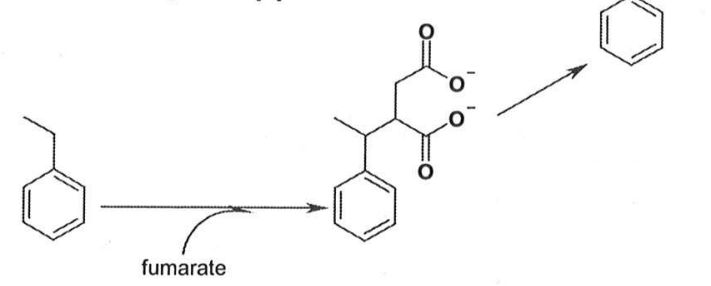

Fig. 2. Initial steps in anaerobic degradation of ethylbenzene. A. Degradation by the nitrate-reducing bacterium 'Aromatoleum aromaticum', leading to (S)-1-phenylethanol.

B. Degradation by the sulfate-reducing bacterium strain EbS7, forming phenylethyl succinate as intermediate.

anae it was suggested earlier that it reduces benzoyl-CoA in a four-electron transfer step to a cyclohex-1-ene derivative (Schöcke and Schink, 1999). Recent evidence (Peters et al., 2004; 2007b; Löffler et al., 2011) indicates that sulfate reducers and syntrophically fermenting benzoate degraders use an ATP-independent reductase system similar to that described above for G. metallireducens. This view is supported by the observation that with the syntrophically fermenting Syntrophus aciditrophicus the pathway from benzoyl-CoA to fatty acid derivatives appears to be fully reversible as well (Mouttaki et al., 2007).

\section{Ethylbenzene}

For the initiating reaction in anaerobic degradation of ethylbenzene, two alternative strategies have been reported. The denitrifying bacteria 'Aromatoleum aromaticum' strain EbN1 (Kniemeyer and Heider, 2001) and Azoarcus sp. strain EB1 (Johnson et al., 2001) initiate degradation of ethylbenzene by hydroxylation to (S)-1-phenylethanol (Fig. 2A). Both enzymes contain molybdenum; the basic mechanism of oxygen-independent hydroxylation is probably analogous to that of other hydroxylating molybdenum enzymes (Hille et al., 1999; Boll et al., 2005). Further degradation leads via oxidation to acetophenone and carboxylation to benzoyl acetate (Heider, 2007). In contrast, the sulfate-reducing bacterium strain EbS7 initiates ethylbenzene degradation by fumarate addition, a reaction mechanism which was originally discovered in sulfate-dependent degradation of toluene (Biegert et al., 1996; Beller and Spormann, 1997). Fumarate addition to ethylbenzene forms (1-phenylethyl) succinate (Fig. 2B), which is further degraded via rearrangement to 4-phenylpentanoyl-CoA (Kniemeyer et al., 2003). Regardless of the different strategies for initiating the conversion, the ethylbenzene residue is channelled into the benzoylCoA pathway in both cases. Since the redox potential for the hydroxylation is rather positive $(-12 \mathrm{mV}$, Johnson and Spormann, 1999; or $+30 \mathrm{mV}$; Kniemeyer and Heider, 2001), this reaction would be difficult to perform by sulfate-reducing bacteria (Kniemeyer et al., 2003).

\section{Cresols}

Cresols (methylphenols) are anaerobically degraded through different pathways, depending on the position of the hydroxy group. $p$-Cresol is hydroxylated by a nitrate reducer at the methyl group by an oxygen-independent reaction, possibly through a quinomethide intermediate as suggested earlier for an aerobic Pseudomonas strain (Fig. 3A; Hopper, 1978). The redox potential of this oxidation reaction is in the range of $+100 \mathrm{mV}$ (calculated after Thauer et al., 1977) and the reaction is therefore easy for a nitrate-reducing bacterium that couples this oxidation, e.g., with the reduction of a $c$-type cytochrome at $+232 \mathrm{mV}$ (Hopper et al., 1991). Recently, a p-cresol methylhydroxylase of $G$. metallireducens has been shown to be a periplasmic enzyme with two haem cofactors and one FAD cofactor (Peters et al., 2007b; Johannes et al., 2008). A sulfate-reducing bacterium uses an entirely different pathway for $p$-cresol degradation, which activates the substrate at the methyl group by fumarate addition (Müller et al., 2001). o-Cresol can be carboxylated by fermenting and by nitrate-reducing bacteria to 3-methyl-4-hydroxybenzoate and degraded further analogous to phenol, producing 3-methyl benzoyl-CoA (Fig. 3B; Bisaillon et al., 1991; Rudolphi et al., 1991). In enrichment cultures with $m$-cresol plus sulfate, indications of a carboxylation as primary activation reaction were obtained (Roberts et al., 1990; Ramanand and Suflita, 1991), but it was never proven that the 4-hydroxy-2-methyl benzoic acid detected was really a degradation intermediate rather than a side product. Degradation of $m$-cresol by the sulfate-reducing bacterium Desulfobacterium cetonicum follows a pathway similar to sulfate-dependent $p$-cresol oxidation, including fumarate addition to the methyl group (Müller et al., 1999). Activation and $\beta$-oxidation lead to succinylCoA and 3-hydroxybenzoyl-CoA (Fig. 3C). Thus again, oxidative activation reactions are used by nitrate reducers whereas sulfate reducers prefer the addition of fumarate to the methyl group.

\section{Resorcinol and resorcylic acids}

There are two different pathways for anaerobic degradation of resorcinol (1,3-dihydroxybenzene), which can be attacked either reductively or oxidatively. Reduction of resorcinol was found with the fermenting Clostridium 
A

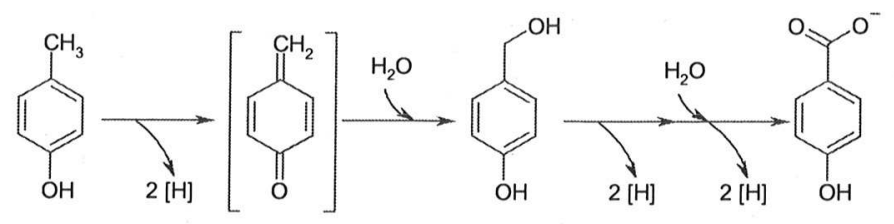

B<smiles>Cc1cccc(C(=O)OCC(C)C(=O)OCC(C)C(=O)O)c1</smiles>

C<smiles>Cc1cccc(O)c1</smiles>

Fig. 3. Initial steps in anaerobic degradation of cresols.

A. Degradation of $p$-cresol.

B. Degradation of $o$-cresol.

C. Degradation of $m$-cresol.

co-culture KN 245 (Tschech and Schink, 1985), which harbours a resorcinol reductase catalysing the reduction of resorcinol to 1,3-cyclohexadione (Fig. 4A; Kluge et al., 1990). This intermediate is hydrolytically cleaved to 5-oxocaproic acid which is further fermented to acetate and butyrate. The resorcinol reductase is a homomultimeric enzyme consisting of $49.5 \mathrm{kDa}$ subunits

A

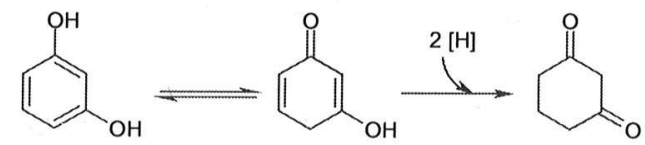

B

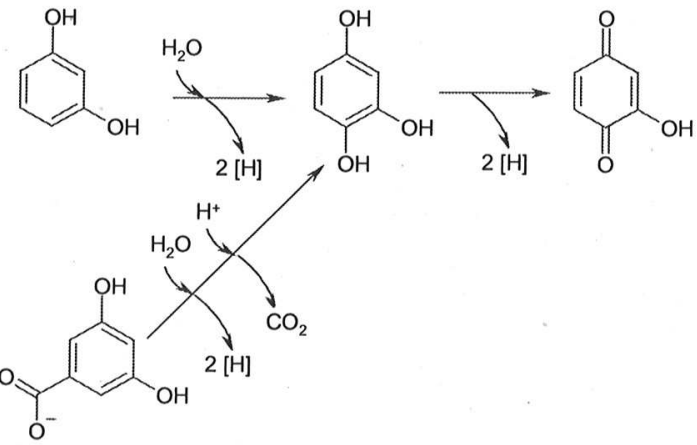

Fig. 4. Initial steps in anaerobic degradation of resorcinol. A. Resorcinol degradation by a fermenting bacterium, Clostridium strain KN245.

B. Degradation of resorcinol and $\alpha$-resorcylate by the denitrifying bacteria Azoarcus anaerobius and Thauera aromatica strain AR-1 respectively. each with FAD as a co-factor (Schüler, 1997). The reduction of resorcinol resembles the analogous reactions with phloroglucinol (1,3,5-trihydroxybenzene; Haddock and Ferry, 1989) and hydroxyhydroquinone (1,2,4trihydroxybenzene; Reichenbecher et al., 2000; see below). In all these cases, the aromatic $\pi$-electron system is sufficiently destabilized to form 1,3-dioxo tautomers and thus to allow ring reduction without prior activation.

An entirely different pathway of resorcinol degradation was found with a nitrate reducing bacterium, Azoarcus anaerobius strain LuFRes1. This pathway proceeds via oxidative steps (Philipp and Schink, 1998), and the respective genes have been identified by heterologous expression in the $T$. aromatica strains AR-1 and K172 (Darley et al., 2007). In the first step, resorcinol is hydroxylated by a membrane-bound enzyme to hydroxyhydroquinone (1,2,4-trihydroxybenzene; HHQ) (Fig. 4B). The resorcinol-hydroxylating enzyme is encoded by two genes named $r h L S$, which show high sequence identities to the subunits of pyrogallol-phloroglucinol transhydroxylase of Pelobacter acidigallici, a wellstudied molybdoenzyme (Reichenbecher et al., 1994; Messerschmidt et al., 2004). Thus, resorcinol hydroxylation is likely catalysed by a molybdenum-containing enzyme. In the second step, $\mathrm{HHQ}$ is further oxidized to hydroxybenzoquinone by a membrane-bound $\mathrm{HHQ}$ dehydrogenase.

Hydroxybenzoquinone, the product of the oxidative de-aromatization, is a very reactive compound which is further converted in cell-free extracts to acetate, malate, and succinate (Darley et al., 2007). The first products of ring cleavage are probably aldehydes or ketones 
since such compounds could be trapped with 2,4-dinitrophenylhydrazine (J. Hellstern, unpubl. results). This reaction sequence is most probably catalysed by enzymes which, according to the gene sequence information, show structural similarity to components of the multienzyme complex pyruvate dehydrogenase. Cleavage of the $\mathrm{HBQ}$ ring through an oxidative splitting between the two oxo carbon atoms would be compatible with an enzymatic system analogous to a pyruvate dehydrogenase complex.

Azoarcus anaerobius strain LuFRes1 can also grow with the resorcylic acids 2,4-dihydroxybenzoate and 2,6-dihydroxybenzoate, which both are prone to spontaneous decarboxylation and are degraded most likely via resorcinol (Gorny et al., 1992). The third isomer 3,5dihydroxybenzoate is chemically stable. T. aromatica strain AR-1 can grow with this compound (Gallus and Schink, 1998) and degrades it via hydroxylation to a trihydroxybenzoate, which is decarboxylated to $\mathrm{HHQ}$ (Fig. 4B). HHQ-dehydrogenating activity was detected in membrane fractions of this strain as well (Philipp and Schink, 2000).

The HHQ-pathway for degradation of aromatic compounds has so far been found only in nitrate-reducing bacteria, probably because the oxidation of resorcinol to $\mathrm{HHQ}$ requires electron acceptors of a positive redox potential (about $+100 \mathrm{mV}$ ). Also the oxidation of $\mathrm{HHQ}$ to $\mathrm{HBQ}$ has a standard redox potential of $+180 \mathrm{mV}$ (Philipp and Schink, 1998), which could explain why this strategy is used only by nitrate-reducing bacteria but - as far as we know - not by sulfate-reducing or fermenting bacteria.

\section{Trihydroxybenzenes}

Among the three trihydroxybenzene isomers, pyrogallol and phloroglucinol are degraded quickly by fermenting bacteria, and were actually the first aromatic compounds degraded by fermentation in pure culture (Schink and Pfennig, 1982). Phloroglucinol (1,3,5-trihydroybenzene) degradation has been studied in detail with Eubacterium oxidoreducens and $P$. acidigallici. It is reduced by an NADPH-dependent reductase to dihydrophloroglucinol (Haddock and Ferry, 1989; Brune and Schink, 1992). Hydrolytic ring cleavage leads to 3-hydroxy-5oxohexanoic acid, which is thiolytically cleaved and oxidized to three acetate residues (Brune and Schink, 1992). This pathway is easy to conceive because the 1,3,5arrangement of the three hydroxyl groups on the aromatic ring allows tautomerization to 1,3,5-trioxocyclohexane to a certain degree which favours a nucleophilic attack on the oxo-carbon groups. The second trihydroxybenzene isomer, pyrogallol (1,2,3-trihydroxybenzene), cannot be hydrolysed or reduced directly but is isomerized to phloroglucinol through a transhydroxylation reaction
A<smiles>Oc1cc(O)cc(O)c1</smiles><smiles>[B]C(C)CC(C)CC1C=CC(=O)C(O)=C1</smiles><smiles>Cc1ccc(O)c(O)c1</smiles>

Fig. 5. Degradation of hydroxyhydroquinone.

A. Degradation by fermenting bacteria.

B. Degradation by nitrate-reducing bacteria.

C. Degradation by sulfate-reducing bacteria.

(Krumholz and Bryant, 1988; Brune and Schink, 1990). The reaction requires 1,2,3,5-tetrahydroxybenzene as a cosubstrate, and the enzyme transfers a hydroxyl group from the tetrahydroxybenzene to pyrogallol, thus releasing phloroglucinol as product and the tetrahydroxybenzene as a co-product (Brune and Schink, 1990; Messerschmidt et al., 2004). The transhydroxylase enzyme contains an iron-sulfur centre and a molybdopterin cofactor (Reichenbecher et al., 1996).

The third trihydroxybenzene isomer, hydroxyhydroquinone (HHQ; 1,2,4-trihydroxybenzene), is converted by the fermenting bacterium Pelobacter massiliensis to three acetate as well (Schnell et al., 1991; Fig. 5A), indicating that also this pathway leads through phloroglucinol. The isomerization to phloroglucinol requires three subsequent transhydroxylation reactions analogous to the pyrogallol-phloroglucinol transhydroxylation (Brune et al., 1992).

Alternative to the strategy of isomerization to phloroglucinol, we found different pathways of $\mathrm{HHQ}$ degradation with nitrate-reducing and sulfate-reducing bacteria. Oxidative degradation of $\mathrm{HHQ}$ by nitrate-reducing bacteria (Fig. 5B) was mentioned above in the context of nitratedependent degradation of resorcinol and resorcylic acids. A further alternative of $\mathrm{HHQ}$ degradation was found with the sulfate-reducing bacterium Desulfovibrio inopinatus. This bacterium metabolizes HHQ to two acetates and two $\mathrm{CO}_{2}$ (Fig. 5C). In the first step, HHQ is destabilized by reduction to dihydro- $\mathrm{HHQ}$, and later acetate and a so far 
non-identified 4-carbon derivative are formed (Reichenbecher et al., 2000). Since D. inopinatus cannot oxidize acetyl residues, the final products are two acetates and two $\mathrm{CO}_{2}$, and $1 \mathrm{~mol}$ of sulfate is reduced concomitantly to sulfide. Thus, the strategies of substrate exploitation by the three different metabolic types of anaerobic bacteria are mirrored in their metabolic products: The fermenting bacterium releases all substrate carbon as acetate, and recovers a net amount of 2 ATP per mol HHQ via phosphotransacetylase and acetate kinase, following one hydrolytic and two thiolytic cleavage reactions. The sulfate reducer which cannot oxidize acetate produces two acetates and uses the additional electrons for sulfate reduction to gain some additional energy through sulfate respiration. The nitrate reducer gains most of its energy in the oxidation of acetyl residues and forms only $\mathrm{CO}_{2}$ as terminal product.

\section{Phenol, hydroquinone, catechol and aniline}

Different from the cases treated so far, anaerobic degradation of other aromatics, such as phenol, hydroquinone and catechol, appears to take similar paths, no matter which electron acceptor is used.

Phenol degradation has been investigated into most detail with the denitrifying bacterium $T$. aromatica strain $\mathrm{K} 172$. It is carboxylated to 4-hydroxybenzoate (Tschech and Fuchs, 1989) via phenylphosphate (Lack and Fuchs, 1992), which is formed by an ATP-dependent reaction yielding phenylphosphate, AMP and inorganic phosphate (Lack and Fuchs, 1994; Schmeling et al., 2004). The subsequent carboxylase forms 4-hydroxybenzoate plus phosphate (Schühle and Fuchs, 2004). Thus, the carboxylation of phenol to phenylphosphate is accomplished with the expenditure of two ATP equivalents. The further degradation of 4-hydroxybenzoate proceeds via activation with coenzyme $A$ and reductive dehydroxylation to benzoyl-CoA; this compound is further degraded via reactions described before (Boll et al., 2002). Also other nitrate reducers such as Magnetospirillum spp. and 'Aromatoleum aromaticum' and even the iron-reducing strict anaerobe G. metallireducens, although energetically far less favoured, all carboxylate phenol via phenyl phosphate at the expense of two ATP equivalents (Schleinitz et al., 2009; Schmeling and Fuchs, 2009). The same appears to be true for the sulfate-reducing Desulfobacterium anilini (Ahn et al., 2009). So far, the biochemistry of phenol carboxylation in fermenting phenol degraders (Gallert et al., 1991) has not been studied; the high energy expenditure of phenol carboxylation and hydroxybenzoic acid activation described above may ask for different biochemical strategies in these bacteria.

Hydroquinone is degraded by sulfate-reducing and fermenting bacteria via carboxylation to gentisate. This car- boxylation could never be studied in cell-free extracts and the energetization of this reaction is unknown. Gentisate is activated to gentisyl-CoA through a CoA-ligase reaction (Gorny and Schink, 1994a,b). In S. gentianae, gentisylCoA is reductively dehydroxylated to benzoyl-CoA which enters a modified benzoyl-CoA pathway (Gorny and Schink, 1994b).

Degradation of catechol has been studied with a sulfate-reducing Desulfobacterium strain, which carboxylates catechol to protocatechuate (Gorny and Schink, 1994c). Protocatechuate is activated to form protocatechuyl-CoA, which is subsequently dehydroxylated to benzoyl-CoA. A similar pathway appears to be used by the nitrate reducer T. aromatica (Ding et al., 2008). In this case, the initial carboxylation proceeds via activation of catechol to catechylphosphate.

Aniline is degraded anaerobically by the sulfate reducer $D$. anilini through a pathway analogous to phenol degradation. It is initially carboxylated to 4-aminobenzoate which is subsequently activated to 4-aminobenzoyl-CoA, with subsequent reductive deamination to benzoyl-CoA (Schnell and Schink, 1991). The carboxylation reaction has not been studied so far, and nothing is known about an activated intermediate to provide the necessary energy for the carboxylation reaction. A primary phosphorylation as in the case of phenol degradation (see above) appears unlikely, but no reliable biochemical studies have been performed on this system yet. Aniline degradation by nitrate reducers or other anaerobes has never been reported yet.

\section{Conclusions}

In this survey, we have shown that the degradation of aromatic compounds by anaerobic bacteria can follow rather different strategies with every substrate, indicating that anaerobic degradation of aromatic compounds is apparently more diverse with respect to the possible intermediates and reaction routes than the aerobic degradation of aromatics. Comparison of fermenting, sulfate-reducing, and nitrate-reducing bacteria exemplifies that the respective strategy applied in the absence of oxygen appears to be largely influenced by the energetic situation of the respective organism and the redox potentials of the electron acceptors it can use. In the benzoyl-CoA pathway, two different strategies are used to overcome the resonance energy barrier to destabilize the $\pi$-electron system: nitrate reducers invest a major amount of ATP into the reduction to the energy-rich cyclohexadiene derivative. Iron-reducing, sulfatereducing and fermenting bacteria do the same without ATP, but shift and pull this reaction by bifurcation of ferredoxin electrons and subsequent dismutation to benzoyl-CoA and the cyclohexene derivative, which is 
energetically more feasible. Thus, the net reduction of benzoyl-CoA to cyclohex-1-ene carboxyl-CoA with four electrons may require only fractions of an ATP equivalent which has to be invested into a reversed electron transport from $\mathrm{NAD}(\mathrm{P}) \mathrm{H}$ to ferredoxin.

In degradation of ethylbenzene and cresols, nitrate reducers start with oxidative steps with standard redox potentials around 0 to $+100 \mathrm{mV}$. Electrons at these potentials are difficult to dispose of by sulfate reducers or other strict anaerobes; iron reducers are just able to handle such electrons as the case of $p$-cresol degradation shows. Sulfate reducers prefer the addition of fumarate to alkyl residues which is nearly an equilibrium reaction $\left(\Delta \mathrm{G}_{0}{ }^{\prime}=-15-25 \mathrm{~kJ} \mathrm{~mol}^{-1}\right)$. Of course, the problem of electron disposal follows then later, in the reoxidation of a succinyl to a fumaryl residue $\left(\mathrm{E}_{0}^{\prime}=+30 \mathrm{mV}\right)$ to complete the reaction cycle. Sulfur- and sulfate-reducing bacteria couple succinate oxidation with a reversed electron transport, which consumes a fraction of an ATP equivalent (Paulsen et al., 1986; Thauer, 1988).

With resorcinol, two entirely different pathways were identified in fermenting versus nitrate-reducing bacteria, the one starting with a reductive, the other one with an oxidative strategy. The $\mathrm{HHQ}$ pathway may gain major importance in the transformation of phenolic compounds by nitrate-reducing bacteria, because they may prefer this pathway over the parallel pathways used by fermenting or sulfate-reducing bacteria. Degradation of $\mathrm{HHQ}$ takes even three different directions, isomerization to phloroglucinol in fermenting bacteria, primary reductive destabilization in sulfate reducers, and oxidative attack in nitrate reducers.

Nonetheless, some compounds are degraded through similar primary activation reactions, no matter which electron donor is used. This applies to phenol, hydroquinone and catechol, at least according to our present knowledge. All these substrates start (after phosphorylation of the respective substrate) with a carboxylation reaction, which is not directly coupled to redox processes and is therefore rather independent of the electron acceptor system.

Finally, some open questions remain with respect to the diversity of anaerobic pathways for degradation of aromatics. Whereas some aromatics, e.g., benzoate, can be degraded under any redox condition discussed, others are degraded only under certain conditions. It appears enigmatic why, e.g., aniline is degraded so far only by sulfate reducers although its degradation with nitrate should be much more feasible. The same applies to anaerobic naphthalene degradation which was shown reliably so far only with sulfate as electron acceptor (Galushko et al., 1999; Musat et al., 2009). Perhaps some key steps in the activation of these substrates interfere with the high reactivity of redox intermediates of nitrate reduction (nitrite, $\mathrm{NO}, \mathrm{N}_{2} \mathrm{O}$ ), which preclude those reactions to proceed.

One may ask why there are different strategies taken for anaerobic degradation of aromatic compounds in the anoxic world. Since fermenting bacteria, sulfate reducers and iron reducers are supposed to have evolved their metabolic capacities far before aerobes and nitrate reducers entered the scene, one may argue that these bacteria could have used the same biochemical strategies as their strictly anaerobic predecessors. However, nitrate reduction was developed probably even after aerobic respiration as a secondary anaerobic lifestyle, and both oxygen and the various redox intermediates of denitrification (nitrite, $\mathrm{NO}, \mathrm{N}_{2} \mathrm{O}$ ) are aggressive oxidants, which probably preclude the employment of highly oxygen-sensitive, often radical-catalysed reactions that the strict anaerobes handle with such impressive virtuosity. Therefore, nitrate reducers had to develop novel oxygen-independent strategies, at least in those cases in which rather delicate radical-catalysed reactions are used by the strict anaerobes.

\section{Acknowledgements}

The authors want to thank the former students in this laboratory, Andreas Tschech, Andreas Brune, Sylvia Schnell, Norbert Gorny, Corinna Gallus, Wolfram Reichenbecher, Jutta Hellstern and Paula Darley, for their dedicated work on various aspects of anaerobic degradation of aromatic compounds. They also appreciate the stimulating and helpful cooperation with their colleagues Georg Fuchs, Wolfgang Buckel, Friedrich Widdel, Johann Heider and Matthias Boll. Work in the author's laboratory has been supported through grants by the Deutsche Forschungsgemeinschaft, the University of Konstanz, and the Fonds der Chemischen Industrie, Frankfurt am Main. All these supports are gratefully acknowledged.

\section{References}

Ahn, Y.B., Chae, J.C., Zylstra, G.J., and Häggblom, M.M. (2009) Degradation of phenol via phenylphosphate and carboxylation to 4-hydroxybenzoate by a newly isolated strain of the sulfate-reducing bacterium Desulfobacterium anilini. Appl Environ Microbiol 75: 4248-4253.

Beller, H.R., and Spormann, A.M. (1997) Benzylsuccinate formation as a means of anaerobic toluene activation by sulfate-reducing strain PRTOL1. Appl Environ Microbiol 63: 3729-3731.

Biegert, T., Fuchs, G., and Heider, J. (1996) Evidence that anaerobic oxidation of toluene in the denitrifying bacterium Thauera aromatica is initiated by formation of benzylsuccinate from toluene and fumarate. Eur $J$ Biochem 238: 661-668.

Bisaillon, J.G., Lépine, F., Beaudet, R., and Sylvestre, M. (1991) Carboxylation of o-cresol by an anaerobic consortium under methanogenic conditions. Appl Environ Microbiol 57: 2131-2134. 
Boll, M. (2005a) Key enzymes in the anaerobic aromatic metabolism catalysing Birch-like reductions. Biochim Biophys Acta 1707: 34-50.

Boll, M. (2005b) Dearomatizing benzene ring reductases. J Mol Microbiol Biotechnol 10: 132-142.

Boll, M., and Fuchs, G. (1995) Benzoyl-coenzyme A reductase (dearomatizing), a key enzyme of anaerobic aromatic metabolism. ATP dependence of the reaction, purification and some properties of the enzyme from Thauera aromatica strain K172. Eur J Biochem 234: 921-933.

Boll, M., and Fuchs, G. (2005) Unusual reactions involved in anaerobic metabolism of phenolic compounds. Biol Chem 386: 989-997.

Boll, M., Fuchs, G., and Heider, J. (2002) Anaerobic oxidation of aromatic compounds and hydrocarbons. Curr Opin Chem Biol 6: 604-611.

Boll, M., Schink, B., Messerschmidt, A., and Kroneck, P.M. (2005) Novel bacterial molybdenum and tungsten enzymes: three-dimensional structure, spectroscopy, and reaction mechanism. Biol Chem 386: 999-1006.

Brune, A., and Schink, B. (1990) Pyrogallol-to-phloroglucinol conversion and other hydroxyl-transfer reactions catalyzed by cell extracts of Pelobacter acidigallici. J Bacteriol 172: 1070-1076.

Brune, A., and Schink, B. (1992) Phloroglucinol pathway in the strictly anaerobic Pelobacter acidigallici: fermentation of trihydroxybenzenes to acetate via triacetic acid. Arch Microbiol 157: 417-424.

Brune, A., Schnell, S., and Schink, B. (1992) Sequential. transhydroxylations converting hydroxyhydroquinone to phloroglucinol in the strictly anaerobic fermenting bacterium. Pelobacter massiliensis. Appl Environ Microbiol 58: 1861-1868.

Carmona, M., Zamarro, M.T., Blázquez, B., DuranteRodríguez, G., Juárez, J.F., Valderrama, J.A., et al. (2009) Anaerobic catabolism of aromatic compounds: a genetic and genomic view. Microbiol Mol Biol Rev 73: 71-133.

Darley, P., Hellstern, J., Medina-Bellver, J.I., Marqués, S., Schink, B., and Philipp, B. (2007) Heterologous expression and identification of the genes involved in anaerobic degradation of 1,3-dihydroxybenzene (resorcinol) in Azoarcus anaerobius. J Bacteriol 189: 3824-3833.

Ding, B., Schmeling, S., and Fuchs, G. (2008) Anaerobic metabolism of catechol by the denitrifying bacterium Thauera aromatica - a result of promiscuous enzymes and regulators? J Bacteriol 190: 1620-1630.

Fuchs, G. (2008) Anaerobic metabolism of aromatic compounds. Ann N Y Acad Sci 1125: 82-99.

Gallert, C., Knoll, G., and Winter, J. (1991) Anaerobic carboxylation of phenol to benzoate: use of deuterated phenols revealed carboxylation exclusively in the $\mathrm{C} 4$ position. Appl Microbiol Biotechnol 36: 124-129.

Gallus, C., and Schink, B. (1998) Anaerobic degradation of a-resorcylate by Thauera aromatica strain AR-1 proceeds via oxidation and decarboxylation to hydroxyhydroquinone. Arch Microbiol 169: 333-338.

Galushko, A., Minz, D., Schink, B., and Widdel, F. (1999) Anaerobic degradation of naphthalene by a pure culture of a novel type of marine sulphate-reducing bacterium. Environ Microbiol 1: 415-420.
Gibson, G., and Harwood, C.S. (2002) Metabolic diversity in aromatic compound utilization by anaerobic microbes. Annu Rev Microbiol 56: 345-369.'

Gorny, N., and Schink, B. (1994a) Complete anaerobic oxidation of hydroquinone by Desulfococcus sp. strain Hy5: indications of hydroquinone carboxylation to gentisate. Arch Microbiol 162: 131-135.

Gorny, N., and Schink, B. (1994b) Hydroquinone degradation via reductive dehydroxylation of gentisyl-CoA by a strictly anaerobic fermenting bacterium. Arch Microbiol 161: 25-32.

Gorny, N., and Schink, B. (1994c) Anaerobic degradation of catechol by Desulfobacterium sp. strain Cat2 proceeds via carboxylation to protocatechuate. Appl Environ Microbiol 60: $3396-3340$.

Gorny, N., Wahl, G., Brune, A., and Schink, B. (1992) A strictly anaerobic nitrate-reducing bacterium growing with resorcinol and other aromatic compounds. Arch Microbiol 158: $48-53$.

Haddock, J.D., and Ferry, J.G. (1989) Purification and properties of phloroglucinol reductase from Eubacterium oxidoreducens G-41. J Biol Chem 264: 4423-4427.

Harwood, C.S., Burchhardt, G., Herrmann, H., and Fuchs, G. (1999) Anaerobic metabolism of aromatic compounds via the benzoyl-CoA pathway. FEMS Microbiol Rev 22: 439458

Healy, J.B., and Young, L.Y. (1978) Catechol and phenol degradation by a methanogenic population of bacteria. Appl Environ Microbiol 35: 216-218.

Healy, J.B., and Young, L.Y. (1979) Anaerobic biodegradation of eleven aromatic compounds to methane. Appl Environ Microbiol 38: 84-89.

Heider, J. (2007) Adding handles to unhandy substrates: anaerobic hydrocarbon activation mechanisms. Curr Opin Chem Biol 11: 188-194.

Heider, J., and Fuchs, G. (1997) Anaerobic metabolism of aromatic compounds. Eur J Biochem 243: 577-596.

Herrmann, G., Jayamani, E., Mai, G., and Buckel, W. (2008) Energy conservation via electron-transferring flavoprotein in anaerobic bacteria. J Bacteriol 190: 784791.

Hille, R., Rétey, J., Bartlewski-Hof, U., Reichenbecher, W. and Schink, B. (1999) Mechanistic aspects of molybdenum-containing enzymes. FEMS Microbiol Rev 22: 489-501.

Hopper, D.J. (1978) Incorporation of $\left[{ }^{18} \mathrm{O}\right]$ water in the formation of p-hydroxybenzyl alcohol by the p-cresol methylhydroxylase from Pseudomonas putida. Biochem $J$ 175: 345-347.

Hopper, D.J., Bossert, I.D., and Rhodes-Roberts, M.E. (1991) p-Cresol methylhydroxylase from a denitrifying bacterium involved in anaerobic degradation of $\mathrm{p}$-cresol. J Bacteriol 173: 1298-1301.

Johannes, J., Bluschke, A., Jehmlich, N., von Bergen, M., and Boll, M. (2008) Purification and characterization of active-site components of the putative p-cresol methylhydroxylase membrane complex from Geobacter metallireducens. J Bacteriol 190: 6493-6500.

Johnson, H.A., and Spormann, A.M. (1999) In vitro studies on the initial reactions of anaerobic ethylbenzene mineralization. J Bacteriol 181: 5662-5668. 
Johnson, H.A., Pelletier, D.A., and Spormann, A.M. (2001) Isolation and characterization of anaerobic ethylbenzene dehydrogenase, a novel Mo-Fe-S enzyme. J Bacteriol 183: 4536-4542.

Kluge, C., Tschech, A., and Fuchs, G. (1990) Anaerobic metabolism of resorcylic acids (m-dihydroxybenzoic acids) and resorcinol (1,3-benzenediol) in a fermenting and in a denitrifying bacterium. Arch Microbiol 155: 68-74.

Kniemeyer, O., and Heider, J. (2001) Ethylbenzene dehydrogenase, a novel hydrocarbon-oxidizing molybdenum/ironsulfur/heme enzyme. J Biol Chem 276: 21381-21386.

Kniemeyer, O., Fischer, T., Wilkes, H., Glöckner, F.O., and Widdel, F. (2003) Anaerobic degradation of ethylbenzene by a new type of marine sulfate-reducing bacterium. Appl Environ Microbiol 69: 760-768.

Koch, J., Eisenreich, W., Bacher, A., and Fuchs, G. (1993) Products of enzymatic reduction of benzoyl-CoA, a key reaction in anaerobic aromatic metabolism. Eur J Biochem 211: 649-661.

Krumholz, R., and Bryant, M.P. (1988) Characterization of the pyrogallol-phloroglucinol isomerase of Eubacterium oxidoreducens. J Bacteriol 170: 2472-2479.

Kung, J.W., Löffler, C., Dörner, K., Heintz, D., Gallien, S., Van Dorsselaer, A., et al. (2009) Identification and characterization of the tungsten-containing class of benzoyl-coenzyme A reductases. Proc Natl Acad Sci USA 106: 17687-17692.

Kung, J.W., Baumann, S., von Bergen, M., Müller, M., Hagedoorn, P.L., Hagen, W.R., and Boll, M. (2010) Reversible biological birch reduction at an extremely low redox potential. J Am Chem Soc 132: 9850-9856.

Lack, A., and Fuchs, G. (1992) Carboxylation of phenylphosphate by phenol carboxylase, an enzyme system of anaerobic phenol metabolism in a denitrifying Pseudomonas sp. J Bacteriol 174: 3629-3636.

Lack, A., and Fuchs, G. (1994) Evidence that phenol phosphorylation to phenylphosphate is the first step in anaerobic phenol metabolism in a denitrifying Pseudomonas sp. Arch Microbiol 161: 306-311.

Löffler, C., Kuntze, K., Vazquez, J.R., Rugor, A., Kung, J.W. Böttcher, A., and Boll, M. (2011) Occurrence, genes and expression of the W/Se-containing class II benzoylcoenzyme A reductases in anaerobic bacteria. Environ Microbiol 13: 696-709.

Messerschmidt, A., Niessen, H., Abt, D., Einsle, O., Schink, B., and Kroneck, P.H.M. (2004) Crystal structure of pyrogallol-phloroglucinol transhydroxylase, an Mo enzyme capable of intermolecular hydroxyl transfer between phenols. Proc Natl Acad Sci USA 101: 11571-11576.

Mouttaki, H., Nanny, M.A., and Mclnerney, M.J. (2007) Cyclohexane carboxylate and benzoate formation from crotonate in Syntrophus aciditrophicus. Appl Environ Microbiol 73: 930-938.

Müller, J.A., Galushko, A.S., Kappler, A., and Schink, B. (1999) Anaerobic degradation of $m$-cresol by Desulfobacterium cetonicum is initiated by formation of 3-hydroxybenzylsuccinate. Arch Microbiol 172: 287-294.

Müller, J.A., Galushko, A.S., Kappler, A., and Schink, B. (2001) Initiation of anaerobic degradation of $p$-cresol by formation of 4-hydroxybenzylsuccinate in Desulfobacterium cetonicum. J Bacteriol 183: 752-757.
Musat, F., Galushko, A., Jacob, J., Widdel, F., Kube, M. Reinhardt, R., et al. (2009) Anaerobic degradation of naphthalene and 2-methylnaphthalene by strains of marine sulfate-reducing bacteria. Environ Microbiol 11: 209-219.

Paulsen, J., Kröger, A., and Thauer, R.K. (1986) ATP-driven succinate oxidation in the catabolism of Desulfuromonas acetoxidans. Arch Microbiol 144: 78-83.

Peters, F., Rother, M., and Boll, M. (2004) Selenocysteinecontaining proteins in anaerobic benzoate metabolism of Desulfococcus multivorans. J Bacteriol 186: 2156-2163.

Peters, F., Shinoda, Y., Mclnerney, M.J., and Boll, M. (2007a) Cyclohexa-1,5-diene-1-carbonyl-coenzyme A (CoA) hydratases of Geobacter metallireducens and Syntrophus aciditrophicus: evidence for a common benzoyl-CoA degradation pathway in facultative and strict anaerobes. J Bacteriol 189: 1055-1060.

Peters, F., Heintz, D., Johannes, J., van Dorsselaer, A., and Boll, M. (2007b) Genes, enzymes, and regulation of para-cresol metabolism in Geobacter metallireducens. J Bacteriol 189: 4729-4738.

Philipp, B., and Schink, B. (1998) Evidence of two oxidative reaction steps initiating anaerobic degradation of resorcinol (1,3-dihydroxybenzene) by the denitrifying bacterium Azoarcus anaerobius. J Bacteriol 180: 3644-3649.

Philipp, B., and Schink, B. (2000) Two distinct pathways for anaerobic degradation of aromatic compounds in the denitrifying bacterium Thauera aromatica strain AR-1. Arch Microbiol 173: 91-96.

Ramanand, K., and Suflita, J.M. (1991) Anaerobic degradation of $\mathrm{m}$-cresol in anoxic aquifer slurries: carboxylation reactions in a sulfate-reducing bacterial enrichment. Appl Environ Microbiol 57: 1689-1695.

Reichenbecher, W., Brune, A., and Schink, B. (1994) Transhydroxylase of Pelobacter acidigallici: a molybdoenzyme catalyzing the conversion of pyrogallol to phloroglucinol. Biochim Biophys Acta 1204: 217-224.

Reichenbecher, W., Rüdiger, A., Kroneck, P.M.H., and Schink, B. (1996) One molecule of molybdopterin guanine dinucleotide is associated with each subunit of the heterodimeric Mo-Fe-S protein transhydroxylase of Pelobacter acidigallici as determined by SDS/PAGE and mass spectrometry. Eur J Biochem 237: 406-413.

Reichenbecher, W., Philipp, B., Suter, M. J.-F., and Schink, B. (2000) Hydroxyhydroquinone reductase, the initial enzyme in the degradation of hydroxyhydroquinone $(1,2,4-$ trihydroxybenzene) by Desulfovibrio inopinatus. Arch Microbiol 173: 206-212.

Roberts, D.J., Fedorak, P.M., and Hrudey, S.E. (1990) $\mathrm{CO}_{2}$ incorporation and 4-hydroxy-2-methylbenzoic acid formation during anaerobic metabolism of $\mathrm{m}$-cresol by a methanogenic consortium. Appl Environ Microbiol 56: 472-478.

Rudolphi, A., Tschech, A., and Fuchs, G. (1991) Anaerobic degradation of cresols by denitrifying bacteria. Arch Microbiol 155: 238-248.

Schink, B., and Pfennig, N. (1982) Fermentation of trihydroxybenzenes by Pelobacter acidigallici gen. nov. sp nov., a new strictly anaerobic non-sporeforming bacterium. Arch Microbiol 133: 195-201.

Schink, B., Brune, A., and Schnell, S. (1992) Anaerobic degradation of aromatic compounds. In Microbial Degradation 
of Natural Compounds. Winkelmann, G. (ed.). Weinheim: VCH, pp. 219-242.

Schink, B., Philipp, B., and Müller, J. (2000) Anaerobic degradation of phenolic compounds. Naturwissenschaften $\mathbf{8 7}$ : 12-23.

Schleinitz, K.M., Schmeling, S., Jehmlich, N., von Bergen, M., Harms, H., Kleinsteuber, S., et al. (2009) Phenol degradation in the strictly anaerobic iron-reducing bacterium Geobacter metallireducens GS-15. Appl Environ Microbiol 75: 3912-3919.

Schmeling, S., and Fuchs, G. (2009) Anaerobic metabolism of phenol in proteobacteria and further studies of phenylphosphate carboxylase. Arch Microbiol 191: 869-878.

Schmeling, S., Narmandak, A., Schmitt, O., Gad'on, N., Schühle, K., and Fuchs, G. (2004) Phenylphosphate synthase: a new phosphotransferase catalysing the first step in anaerobic phenol metabolism in Thauera aromatica. J Bacteriol 186: 8044-8057.

Schnell, S., and Schink, B. (1991) Anaerobic aniline degradation via reductive deamination of 4-aminobenzoyl CoA in Desulfobacterium anilini. Arch Microbiol 155: 183-190.

Schnell, S., Brune, A., and Schink, B. (1991) Degradation of hydroxyhydroquinone by the strictly anaerobic fermenting bacterium Pelobacter massiliensis sp. nov. Arch Microbiol 155: 511-516.

Schöcke, L., and Schink, B. (1999) Biochemistry and energetics of fermentative benzoate degradation by Syntrophus gentianae. Arch Microbiol 171: 331-337.

Schühle, K., and Fuchs, G. (2004) Phenylphosphate carboxylase: a new $\mathrm{C}-\mathrm{C}$ lyase involved in anaerobic phenmol metabolism in Thauera aromatica. J Bacteriol 186: 45564567.
Schüler, K.H. (1997) Isolierung und mechanistische Untersuchung der Resorcin-Reduktase in Clostridium KN245. Diploma Thesis. Konstanz, Germany: Universität Konstanz.

Thauer, R.K. (1988) Citric-acid cycle, 50 years on. Modifications and an alternative pathway in anaerobic bacteria. Eur $J$ Biochem 176: 497-508.

Thauer, R.K., Jungermann, K., and Decker, K. (1977) Energy conservation in chemotrophic anaerobic bacteria. Bacteriol Rev 41: 100-180.

Thauer, R.K., Kaster, A.K., Seedorf, H., Buckel, W., and Hedderich, R. (2008) Methanogenic archaea: ecologically relevant differences in energy conservation. Nat Rev Microbiol 6: 579-591.

Tschech, A., and Fuchs, G. (1989) Anaerobic degradation of phenol via carboxylation to 4-hydroxybenzoate: in vitro study of isotope exchange between ${ }^{14} \mathrm{CO}_{2}$ and 4-hydroxybenzoate. Arch Microbiol 152: 594-599.

Tschech, A., and Schink, B. (1985) Fermentative degradation of resorcinol and resorcylic acids. Arch Microbiol 143: $52-59$.

Vaillancourt, F.H., Bolin, J.T., and Eltis, L.D. (2006) The ins and outs of ring cleaving dioxygenases. Crit Rev Biochem Mol Biol 41: 241-267.

Widdel, F., Schnell, S., Heising, S., Ehrenreich, A., Aßmus, B., and Schink, B. (1993) Anaerobic ferrous iron oxidation by anoxygenic phototrophs. Nature 362: 834-836.

Wischgoll, S., Heintz, D., Peters, F., Erxleben, A., Sarnighausen, E., Reski, R., et al. (2005) Gene clusters involved in anaerobic benzoate degradation of Geobacter metallireducens. Mol Microbiol 58: 12381252. 